\title{
Cultural beliefs and practices of women influencing home births in rural Northern Ghana
}

This article was published in the following Dove Press journal:

International Journal of Women's Health

\author{
Peter Adatara' \\ Johanita Strumpher ${ }^{2}$ \\ Esmeralda Ricks ${ }^{2}$ \\ Prudence Portia Mwini- \\ Nyaledzigbor' \\ 'Department of Nursing, University of \\ Health and Allied Sciences, Ho, Ghana; \\ ${ }^{2}$ Department of Nursing, Nelson \\ Mandela University, Port Elizabeth, South \\ Africa
}

Background: One of the maternal health care strategies identified by the World Health Organization as being crucial for saving lives of pregnant women, which also serves as an indicator for progress in reducing maternal mortality, is the provision and utilization of skilled birth care. Despite the importance of skilled birth care in preventing maternal morbidity and mortality, many women continue to give birth at home without the assistance of skilled birth attendants in rural communities of Ghana.

Purpose: The purpose of this study was to explore the cultural beliefs that potentially influenced the choice of home births among rural women in Ghana.

Methods: A qualitative approach was utilized to conduct this study. Twenty participants who delivered at home were purposefully selected and interviewed individually. Semi structured interviews were used to explore the cultural belief patterns that potentially influenced the choice of home births among women in rural Ghana. Thematic analysis approach was used to analyze the data.

Results: Four major themes emerging from the data analysis which influenced rural women's decision to give birth at home are namely: opportunity to access psychological support through family members, opportunity to access culturally acceptable food, opportunity to adopt a birthing position of choice, and opportunity for safe and culturally accepted disposal of placenta.

Conclusion: This study concluded that the cultural beliefs held by these women greatly affected their decision to deliver at home. Hence, there is a need for health care managers to facilitate collaborative practices between the skilled birth attendants and traditional birth attendants. This is because this approach could enhance the integration of the cultural beliefs and practices of women in the orthodox health care delivery system to facilitate the utilization of skilled birth care.

Keywords: cultural beliefs, perceptions, laboring women, home birth care, skilled birth attendants

\section{Introduction}

One of the maternal health care strategies that were identified by the World Health Organization as being crucial for saving the lives of pregnant women is the provision and utilization of skilled birth care. ${ }^{1}$ Skilled birth attendance has been identified by many maternal health experts as an intervention that could avert many of the preventable maternal and infant deaths, particularly in developing countries. ${ }^{2}$ The World Health Organization has indicated that inadequate utilization of skilled birth care services in sub-Saharan Africa is a major hindrance to efforts aimed at improving the health of women, especially during delivery. Skilled birth care
Correspondence: Peter Adatara University of Health and Allied Sciences, PMB 3I, Ho, Ghana

Tel +23320776742

Email padatara@uhas.edu.gh 
provided by health care professionals during childbirth is one of the key indicators for achieving Sustainable Development Goals. ${ }^{3}$

According to the WHO, a skilled birth attendant, "refers exclusively to people with midwifery skills (for example, doctors, midwives, nurses) who have been trained to be proficient in the skills necessary to provide competent care during pregnancy and childbirth". 4 Globally, the WHO has reported that about one in five births (22\%) take place without the assistance of a skilled birth attendant in 2015 alone. $^{3}$ Additionally, the WHO reported in 2016 that the coverage of skilled birth attendance across regions ranges from $99 \%$ in Eastern Europe, Central Asia, and Western Europe to $52 \%$ in West and Central Africa. ${ }^{3}$ The World Bank has also emphasized the importance of skilled birth care in reducing maternal deaths, indicating all countries where skilled birth care attendance is higher than $80 \%$ have maternal mortality rate less than 200 per 100,000 live births. ${ }^{4}$ It was estimated that inadequate or non-existent care during pregnancy, and delivery was largely responsible for the annual deaths of an estimated 303,000 mothers and 2.7 million newborns in the first month of life in 2015, a huge figure that reflects the need for investments in skilled birth care. ${ }^{5}$

Despite the importance of skilled birth care in preventing maternal mortality and morbidity, empirical studies show that many women still deliver at home without the assistance of skilled birth attendants in sub-Saharan African and other low-resource settings, particularly in rural and deprived areas. ${ }^{6}$ In sub-Saharan Africa, many women deliver their babies at home mostly assisted by traditional birth attendants (TBAs) and untrained family members despite several measures and interventions put in place by governments and other stakeholders to facilitate the utilization of birth care provided by skilled birth attendants. ${ }^{6}$ TBAs are non-trained birth care providers who assist women during childbirth at home in rural areas. ${ }^{7}$ TBAs are integral members of their communities and provide an important window to local customs, traditions, and perceptions regarding childbirth and newborn care.

In the West African region, research shows that despite the high maternal mortality rates, most countries experience low utilization of skilled birth care. ${ }^{4}$ In Ghana, statistics from the Ghana Health Service revealed skilled birth attendance delivery coverage of $56.2 \%$ in 2016 , in spite of Ghana government's policy that makes maternal health services including skilled birth care free of charge in all public and private health institutions. ${ }^{8}$ Also, there still remain significant disparity between the utilization of skilled birth care services in the urban and the rural areas. Whereas in the urban cities, utilization of skilled birth care was more than $70 \%$, in the rural areas, on the other hand, utilization of skilled birth care was less than $50 \%$ meaning that there is inadequate utilization of skilled birth care. The situation is worse in some remote parts of the country, especially rural communities where traditional beliefs and practices associated with childbearing are widely practiced. ${ }^{9}$ In these settings, the situation can be described as bad as more than $30 \%$ of the women deliver at home without the assistance of a trained birth attendant. ${ }^{10}$

In spite the low patronage of skilled birth care by the rural women, there is a paucity of literature regarding the cultural beliefs that are influencing home births among women, although previous studies from other regions of Ghana indicate that lack of financial or economic resources, transportation, and the delivery of supplies at facilities prevented women from using facility-based services. ${ }^{11-16}$ Majority of these studies have been urbanfocused and consequently, the role of cultural beliefs and practices of rural women influencing the use of birth care provided by TBAs have been less discussed or studied. We do not clearly understand the reasons accounting for home births from a cultural perspective from the perspective of the rural northern women. Hence, our purpose in this study is to explore the cultural and contextual factors including practices, beliefs, and traditions, which potentially influence the choice of home childbirth care.

\section{Design and method Research design}

A qualitative approach, using an explorative and descriptive design, was implemented for this study as it enabled the researchers to investigate the full nature of the phenomenon as it occurs in the natural setting. The researchers utilized semi-structured interviews with women who chose to give birth at home in rural communities in a district in the Upper East Region of Ghana. Data were analyzed using a thematic analysis.

\section{Research setting}

The research was carried out in the Bongo district in the Upper East Region of Ghana. The district was selected as the setting for conducting the study because it is one of the most deprived districts in Ghana, and it has all the 
characteristics of a typical rural area in Ghana. A rural area in Ghana describes the remote and deprived settlements that are predominantly dispersed with traditional rural villages. ${ }^{10}$ The quality of life in rural villages is generally poor, marked by poverty and lack of access to social and health care services. The Bongo District is one of the most deprived districts in Ghana and has all the characteristics of a typical rural area in Ghana. Also, the district was chosen because the district is one of the districts in Ghana with low utilization of skilled birth care provided by skilled birth attendants. Ninety-four percent (94\%) of the people live in the rural areas. ${ }^{10}$ According to the Bongo District Health Directorate, there is only one doctor who doubles as the Medical Superintendent, overseeing the District Hospital and manages the work of 65 nurses. ${ }^{11}$ The doctor is a general practitioner. The rest of the maternity units are only manned by midwives providing primary maternity care for women during their pregnancy and childbirth. ${ }^{11}$

\section{Study population and sampling method}

The study population comprised women who delivered at home six months prior to the data collection in rural communities in a district in the northern part of Ghana. As indicated earlier, a rural area describes the remote and deprived settlements that are predominantly dispersed with traditional rural villages. ${ }^{10}$ Purposive sampling was specifically used to select 20 women from rural communities in a district in the northern part of Ghana. Purposive sampling was used because the researcher selected participants, and contexts based on who can give the most and the best information about the research topic and objectives. The inclusion criterion was women who had delivered live and healthy babies at home six months prior to data collection. The women must have been assisted by TBAs or family members during childbirth. The selected women's babies at the time of the study should have been thriving and healthy.

\section{Data collection}

Data were collected through semi-structured interviews. The interviews took place in safe, quiet, and comfortable places, such as community social centers, that were chosen by the participants. The first author carried out all the interviews as he is fluent in both Frafra and English. The first author is also a well-respected member of the community as he has been working over the past five years as a nurse in the community. The individual interviews were carried out at the community social centers which were the most preferred venues for the participants because those venues were free from interruptions. According to the participants, the community social centers would enable participants to speak freely with the researchers about their experiences without any fear of victimization by health care providers. In view of the above concern of the participants, all the individual interviews were conducted at the community social centers. All the participants who agreed to take part in the research signed the consent form after reading and explaining to them the purpose of the study. The interviews lasted between 45 and 60 mins. The interviews were recorded and immediately transcribed verbatim. The anonymity of the study participants was maintained by allocating a number to each interview. Data collection continued until data saturation occurred whereby no new information was forthcoming.

\section{Data analysis}

Thematic analysis approach was used to analyze data as it is particularly indicated for exploratory qualitative studies. ${ }^{1}$ Thematic analysis is one of the most common forms of analysis in qualitative research. It emphasizes pinpointing, examining, and recording patterns within data. ${ }^{1}$ Themes are patterns across data sets that are relevant to the description of a phenomenon and are associated with a specific research question. ${ }^{1}$ Data analysis occurred concurrently with data collection in order to condense the raw data and provide a detailed and thick description of the phenomenon of interest. Interviews were transcribed, read, and reread to identify the important themes and categories, and sorted to sub-themes to reconstruct to a description of how cultural beliefs and practices influence the choice of place for childbirth. Transcripts were read several times to develop a coding framework, which was finalized through consensus between co-authors. Data from all sources, including field note and individual interviews with participants, were analyzed to inductively derive patterns or themes from the data (Munhall, 2001). Allowing participants' voices to emerge and be reflected in the data analysis was central to the research process. To ensure that we accurately reported what our participants said, we went back to the field to check the accuracy of the transcripts with six of them. The verbatim reports were then re-read using the audio recordings in order to validate them, and thus, ensure the reliability of opinions. Also, transcripts from the audio-taped interviews were made and were sent to an independent coder who has experience in 
qualitative data analysis at the Ph.D. level, together with a data analysis guide. The use of an independent coder was to assist in the exclusion of biases by the researcher and to control potential haphazardness with the data analysis. The interviews were analyzed according to the protocol used by the researcher. The independent coder was instructed to use the data analysis guide provided to analyze data from the transcribed interviews so as to assist in excluding the biases of the researcher. The data analysis occurred independently, and the researcher and the independent coder met after the completion of the individual analysis for consensus discussions. These discussions assisted in reducing the data to categories and sub-categories and main emergent themes.

\section{Trustworthiness/Rigour}

Rigour was demonstrated through efforts made by the researchers to confirm information that was discovered and to ensure that the information accurately represents the study participants' view. The researchers ensured trustworthiness in the analysis by a detailed description of the research processes to ensure that, where appropriate, findings can be transferred to other settings. In this study, peer examination took place through discussion of the research process and findings with the independent coder who is an experienced qualitative researcher and the two other research members who had lots of experiences with qualitative research methodologies at the doctoral level. Using the services of an independent coder ensured the trustworthiness of the research findings. All interviews were audio recorded. A detailed description of the research processes was documented to ensure that, where appropriate, findings can be transferred to other settings.

\section{Results}

\section{Characteristics of the participants}

The characteristics of the participants show that majority $(n=19)$ of them belonged to the Frafra ethnic group whilst one $(n=1)$ belonged to the Builsa ethnic group. Twelve $(n=12)$ of the participants were married, six $(n=6)$ were single parents and two $(n=2)$ were widowed. The youngest participant was 18 years and the oldest was 40 years. Seven $(n=7)$ of the participants were within the age range of 15-20 years. The majority $(n=16)$ of the women who participated in the study had no formal education. Only four $(n=4)$ of the participants had formal education up to the primary or Junior High School level or had dropped out at various stages of the 3-year Junior High School period. Also, the majority $(n=17)$ of the participants was engaged in farming activities of various kinds to earn a living. The parity of participants ranged from one to six children.

\section{Themes}

Four main themes emerged from the data analysis, including:

1. Opportunity of accessing psychological support through family members;

2. Opportunity to adopt a birthing position of choice;

3. Opportunity to access culturally acceptable food; and

4. Opportunity for safe and culturally accepted disposal of placenta.

\section{Theme I: Opportunity of accessing psychological support through family members}

According to the participants, one reason that made them to prefer home delivery to skilled birth attendants was the availability or the opportunity for family members to be with the birthing woman when delivery assistance is being sought from a TBA. According to the participants, when they give birth at home, their mothers and other women could stay close to provide support, including back massage during childbirth which help them a lot in supporting the laboring woman to go through the delivering process without any anxiety or pain. Yet in health care facilities, family members are not permitted to enter the delivery room to offer support to the laboring woman. This was captured in the quotes below:

When I delivered my current baby at home, the way they treated me, I didn't even feel the pain during the delivery. My mother and other women were with me, and they were singing, and others were massaging my back and praising me throughout till I delivered. (Participant 12)

One thing I like about home delivery is that the TBA would rather even invite experienced elderly women and other family members to support you when you are in labour, but in the hospital, the nurses will just sack everybody, including your own mother or mother-in-law who could have stayed close to you and offered you support while you go through the labour. (Participant 14)

The participants also reported that the TBAs are very good at maintaining the confidentiality of the birthing woman 
and the delivering process, such as not exposing them to so many people during childbirth as compared to the health facilities. Participants indicated the TBAs are very secretive about what happened during and after delivery and would not permit anybody who was not involved in the delivery process to watch them, unlike in the health facility, where they could allow many people, including students to watch their nakedness. They indicated that in the healthcare facility, nurses and midwives could disclose a woman's confidential information to another colleague about what has happened during the delivery process. The participants noted:

There is privacy when you deliver at home. As for privacy, there is no privacy in the hospital. The last time I delivered my second child at Bongo District Hospital, the nurses who were in the delivery room were more than five. Sometimes in the presence of all these people, they would just be insulting and shouting at you. (Participant 13)

As for delivering at home, one good thing about it is that nobody would be talking about you after delivering by saying 'oh she passed stool when she was about to deliver and was asked to push 'or 'she urinated on herself on the labour table'. You won't hear such stories from the TBA unlike those small, small nurses who talk carelessly. (Participant 18)

If you deliver at home by a TBA or any relative, they would treat you very well. They would praise you and support you to go through the delivery process without feeling any pain. But in the hospital, the nurses would just be behaving as if they don't want you to come to them to have your child (Participant 03).

\section{Theme 2: Opportunity to adopt a birthing position of choice}

The participants reported that the flexible choice of birthing position was another factor that made them prefer home delivery with the assistance of TBAs to skilled birth care attendants. Most of the participants reported that unlike the healthcare facilities where women are compelled to adopt only the supine position in giving birth, the TBAs are flexible and a woman could adopt any position she feels comfortable with, provided it would not harm the mother and the unborn child. They indicated that at home women could give birth in a sitting position on a stool, squatting or standing and holding a wall depending on the individual's interest. These positions, women explain, are comfortable and facilitate an easy delivery. The participants expressed their views as indicated in the excerpts that followed.

One thing I liked about the TBA was that she asked me to sit on a stool and when I realised that I was not comfortable sitting and I told her about it. She then asked me to squat and see whether that was what I was comfortable with, and I did so. She assisted me to squat, I was in that position till I delivered my baby. (Participant 17)

Oh, yes. If it is in the house, you will be allowed to adopt any position you wanted. Sometimes, you can even squat or kneel down if you want, but you won't be allowed to do that in the hospital. The nurses will ask you whether you want to kill your baby, and if you are not lucky, they will slap you. (Participant 15)

Some of the participants, especially those who have their first child, indicated that during childbirth at home, a TBA usually teaches them the various birthing positions that could be adopted by women during childbirth. Yet in the health facility-based delivery, laboring women are usually not taught about the birthing positions as well as advantages and disadvantages associated with each birthing position. The flexibility and education on the birthing positions that are provided at home by TBAs influenced some of women to want to deliver at home.

[...] I think that in terms of birthing position, home delivery is better because at home, the TBA usually, as part of the cultural norms, teaches women who are giving birth for the first time tips on the labour process and the birthing position a woman can assume to minimise labour pain. These tips have, helped many women who gave birth at home, motivating them to want to deliver at home assisted by TBAs. (Participant 13).

I enjoyed giving birth at home because the TBAs taught me the various birthing positions and breathing techniques to facilitate easy delivery. (Participant 14)

\section{Theme 3: Opportunity to access culturally acceptable food}

The study participants acknowledged that they gave birth at home due to the opportunity to eat culturally acceptable food such as hot "zoomkom" (a local drink rich in vitamin C prepared from millet) or "puusakoom" (a local drink prepared from fruits) after childbirth at home. The participants felt that nutritious food prepared at home for women after childbirth was pivotal as these dishes and could 
influence women's decision to deliver at home. The views of women were expressed in the following quotes:

You know after giving birth, you are always weak and hungry. So, they need to give you something to eat; not just anything but something that will make you strong, again. So, they give you "zoomkom" warm water first to give you energy and to cleanse your mouth (that is traditional way of referring to an appetiser) and to help cleanse your stomach of all the dirt following the child birth. This is then followed with tuozaafi (local diet prepared from cereals), which will further boost your strength. The "zoomkom" also helps you to produce more breast milk for your baby. (Participant 19)

When you deliver at home, your people would take good care of you. They would boil water for you to bath and prepare warm water (zoomkom) for you to drink, and tuozaafi for you to eat to regain your strength. You might not get all those treats when you deliver at the hospital. (Participant 16)

Study participants expressed concerns that in the health facility-based birthing situation, women are usually compelled to eat whatever is available and not what the women want to eat during childbirth. They also indicated that sometimes, relatives who make the effort to bring home made dishes are denied entry to health facilities.

I was denied food such as zoomkom and tuozaafi when I delivered my second child in the hospital. My mother inlaw brought tuozaafi for me when I delivered but the midwife on duty that day didn't allow her to bring the food for me. I was compelled to eat rice which was bought for me in the hospital. (Participant 12)

\section{Theme 4: Opportunity for safe and culturally accepted disposal of placenta}

The results revealed that the disposal of the placenta according to the culturally acceptable way after childbirth was one of the norms women associated with home births in the rural areas of Ghana. The participants indicated that certain cultural practices such as taking the placenta home to be buried made them prefer giving birth at home as exemplified in the below quotes:

I gave birth at home. This is because I wanted the placenta to be buried at home according to the dictates of my tradition. If I were to deliver at the health facility, they (nurses) would not have allowed me to take the placenta home for burial according to my tradition. (Participant 03)
[...]. I must admit that I gave birth at home because I wanted my family to have the opportunity bury my child's placenta in order to preserve his destiny of my child, unlike in the health facilities where they are usually disposed by burning. (Participant 06)

As clearly articulated in some excerpts, participants believed that the future of their children depended partly on how the placenta is being disposed of after birth. These were expressed in the following quotes:

We delivered at home because we wanted to preserve the future of our children. The future of our children depends largely on how the placenta is being disposed off after birth. (Participant 07)

[...]. As for me, I don't want my child to grow up and becomes a useless person in the society. I want my child to grow up and become useful person in the society. And so, the way the placenta is dispose of after giving birth matters a lot. (Participant 09)

Some participants attributed the current spate of armed robbery, prostitution, and other social vices in the society to how the placentas of children are disposed of after birth. They indicated that in the case of home births, the placentas are taken outside the house to be buried by a relative to preserve the future of the child. Unlike what obtains in health facility-based births, where the placentas, are usually burnt or incinerated. Participants indicated the perception that placentas of children are usually burnt by health care personnel caused women to give birth at home instead of in the health care facility. Laboring women cherished their control of the placenta after birth.

We are told that when you give birth in the health facility, the nurses would not give you the placenta of your child to be buried at home according to our tradition. So, I decided to give birth at home so as to avoid my child's placenta being burnt to destroy my child's future. (Participant 10)

I didn't want my child's placenta to be burnt. This is because when you give birth in the health facility, the health personnel burn the placenta. This is why so, I gave birth at home so as to save my child destiny. (Participant 11)

Another participant indicated that she gave birth at home because in some health facilities in the rural areas, the placentas are disposed of in an open place or buried in places where animals such as dogs and pigs can easily have access to them. 
As for me, I heard from women who delivered in the health facility that when they gave birth in the health facility, the nurses gave the placenta to the labourers to dispose off by burying them in a nearby place. And sometimes, dogs and pigs remove them to eat. This made me to give birth at home to avoid animals eating my child's destiny. [...] how can I go and deliver in the hospital and my child's placenta would be buried anyhow for pigs and dogs to eat? It would destroy my child future.(Participant 04)

\section{Discussion}

The purpose of this study was to explore and describe the cultural beliefs and perceptions of women that influence their choice for home births over health-facility births in the rural communities in northern Ghana. It came to light from the findings that cultural beliefs play a significant role in influencing the choice of birthing place for women in rural areas of northern Ghana. The results of this study showed that one of the cultural beliefs of women that influenced home birth was the opportunity of accessing psychological support through family members. Our findings corroborate with a study conducted among rural women in the Lao People's Democratic Republic that indicate refusal by women to give birth in health facilities in the country owing to the perception that their family members were not permitted to enter the labor room to stay close to the women and provide psychological support, as well as physical care, including back massage and gentle touching of the abdomen, soothing the woman in labor, and making her feel warm. Some of the participants in this study felt that the absence of a mother or mother-inlaw or any elderly family member was a breach of their cultural practice. ${ }^{17}$ The findings showed that laboring women usually need family members to be around them to offer support during and after birth. These findings call for the amendment of protocols in health care facilities and the development of strategies that allow specific relatives into the labor rooms in health care facilities to offer psychological support to laboring women and to facilitate the utilization of skilled birth care in rural communities in developing countries, including Ghana.

Furthermore, the results of this study showed that the opportunity for laboring women to adopt a birthing position of their choice during labor influenced women's decision to give birth at home. Similar research finding was reported in a study conducted in rural Zambia, which reported that women gave birth at home because TBAs adopted practices which they felt were beneficial for their wellbeing aside the fact that they considered it as culturally accepted. This includes the upright birthing position adopted by TBAs during childbirth. ${ }^{18}$ In another study conducted in rural Bangladesh to explore reasons for preference of home delivery with TBAs, it was reported that the opportunity for laboring women to adopt a birthing position of their choice coupled with other cultural beliefs of women influenced home births. $^{19}$ Culture plays a major role in the way a woman perceives and prepares for her birthing experience. Our study participants felt that the strict adherence to a birthing position in the health facility, unlike home birth where women can adopt any birthing position, was not motivating women to utilize skilled birth care. The current findings suggest that certain traditional beliefs concerning childbirth are of special value to women in Ghana, and therefore, need to be respected by skilled birth attendants to facilitate the utilization of skilled birth care in the rural communities in Ghana.

The opportunity to eat culturally acceptable food during childbirth was reported by our study participants as one of the main reasons that accounted for the decision to give birth at home. Findings from our study reflect the research of others that indicate that women prefer to be attended to during childbirth by TBAs because of the opportunity to eat culturally acceptable food during childbirth and other community norms and customs.$^{20-22}$ Participants in our study expressed their desire to give birth in their home because of the fact that when they give birth at home they have the opportunity to access culturally acceptable food such as hot "zoomkom" (a local drink prepared from millet) or "puusakoom" (a local drink prepared from fruits). Participants held the view that the cultural practice of giving home-made food after birth plays a very important role in replenishing the strength as well as to fight post-delivery infections. It also boosts the woman's appetite since the fruits contain Vitamin C, which is good for immunity. A similar finding was reported in a recent research study conducted in Ghana to explore the reasons associated with home births, expressing the point that lack of culturally acceptable food during childbirth in health facilities was one of the main reasons that accounted for women decided to give birth at home. ${ }^{23}$ The findings of this study highlighted the need for skilled birth care providers in rural areas to encourage women to be given culturally accepted nutritious foods during labor and after delivery. 
Finally, lack of opportunity for safe and culturally accepted disposal of the placenta was revealed in this study as a cultural belief and practice that influenced the choice of home birth among women in rural northern Ghana. The current research finding confirms the findings of previous studies conducted elsewhere in Africa which affirmed that certain cultural practices such as disposal of the placenta in accordance with women's tradition accounts for the preference of home births among women. ${ }^{24,25}$ In another study conducted by Sychareun and colleagues in rural Lao, a setting other than Africa indicated that cultural insensitivity on the part of health care providers during childbirth significantly discourages women from seeking skilled birth care. ${ }^{17}$ Our study reinforces the findings of a recent study carried out in the northern part of Ghana to explore the barriers to utilization of skilled birth care. It discovered in that study that safe disposal of the placenta at home according to the dictates of tradition after birth was one of the reasons that accounted for the choice of home births. ${ }^{23}$ Our study participants held the view that the way the placenta is disposed of greatly determines the destiny and prospects of the child in later life. It must be stated that researchers' observations during visits to some of the health facilities revealed that the placentas are not usually burnt but that they are disposed of as medical waste. However, because the process of disposal never involves the relatives of the mother nor the consent of the client sought, it has always created the perception of women and family that the placentas are usually burnt. The findings of this study highlighted the need for the integration of the traditional beliefs and practices of women into the orthodox medical practice in Ghana, particularly in the rural areas in Ghana.

We believe that the findings from this study can contribute to a growing body of knowledge that supports a context-specific understanding of the practices, beliefs, and traditions influencing childbirth in rural northern Ghana.

\section{Conclusion}

It was concluded that cultural beliefs and perception of rural women in the Bongo district such as opportunity of accessing psychological support through family members, opportunity to access culturally acceptable food, opportunity to adopt a birthing position of choice, opportunity for safe and culturally accepted disposal of placenta greatly influenced the women's decision to deliver at home in rural communities in the Bongo district of Ghana. There is a need for healthcare managers to facilitate collaborative practice between the skilled birth attendants and TBAs. Such collaborative birth care among practitioners would facilitate the integration of the cultural beliefs and practices of women in the orthodox health care delivery system.

\section{Implication for nursing practice}

The results of this study provide a useful first step toward identifying specific cultural beliefs among women in the rural areas in Ghana. The results of this study point to the fact that there is a need for health care managers in rural communities in Ghana to develop policies and strategies to facilitate the integration of the cultural beliefs and practices of women in the health facilities. Health care managers should facilitate a collaborative practice between the skilled birth attendants and TBAs. Such collaborative birth care among practitioners would facilitate the integration of the cultural beliefs and practices of women in the health care delivery system will facilitate the use of birth care services that are provided by skilled birth attendants.

\section{Ethics approval and consent to participate}

This study was conducted in accordance with the Declaration of Helsinki. Ethics approval was obtained from the Nelson Mandela University Post Graduate Research Studies Committee Reference Number: H14-HEA-NUR -30. A verbal approval was granted by the IRB of Ghana Health Service. A verbal approval was granted by the Bongo District Director of Health Service in the Upper East Region of Ghana. The ethical principles of respect for persons, beneficence, and justice were adhered to throughout the study. Written informed consent was obtained from all participants prior to conducting the semistructured interviews.

\section{Availability of data and materials}

The transcripts from which this manuscript was developed are available on request from the corresponding author.

\section{Author contributions}

All authors contributed toward data analysis,drafting and critically revising the paper,gave final approval for the version to be published, and agreed to be accountable for all aspects of the work.

\section{Disclosure}

The authors report no conflicts of interest in this work. 


\section{References}

1. WHO, ICM, FIGO. Making Pregnancy Safer: The Critical Role of Skilled Attendants: Statement. Geneva: WHO; 2004.

2. De Brouwere V, Lerberghe WV. Safe motherhood strategies: a review of the evidence. Stud Health Serv Organ Policy. 2001; 17:1-448.

3. WHO. Maternal Mortality Fact Sheet. Geneva: World Health Organization; 2016.

4. WHO. World Health Report 2005. Make every mother and child count. Geneva: World Health Organization. 2005.

5. United Nations Population Fund. Giving Birth Should Not Be a Matter of Life and Death. New York: UNFPA; 2016.

6. Carlough M, McCall M. Skilled birth attendance: what does it mean and how can it be measured? A clinical skills assessment of maternal and child health workers in Nepal. Int $J$ Gynaecol Obstetrics. 2005;89(2):200-208. doi:10.1016/S0020-7292(05)00174-8

7. Creswell JW. Research Design: Qualitative, Quantitative, and Mixed Methods Approaches. 3rd ed. California: Sage Publications Inc; 2009.

8. Ghana Health Service. Annual Report. Accra: Ghana Health Service; 2016.

9. Ghana Statistical Service. Ghana Multiple Indicator Cluster Survey with an Enhanced Malaria Module and Biomarker. Final Report. Accra, Ghana :Ghana Statistical Service; 2012.Available at:https:// www.measuredhs.com/what-we-do/survey/survey-display-398-cfm. Accessed February 2018

10. Bongo District Health Directorate. Annual Report. Bongo: Bongo District Health Directorate; 2015.

11. Idris SH, Sambo MN, Ibrahim MS. Barriers to utilisation of maternal health services in a semi - urban community in northern Nigeria: the clients' perspective. Int J Maternal Child Health. 2013;54(1): 27-32

12. Ganle JK, Parker M, Fitzpatrick R, Otupiri E. A qualitative study of health system barriers to accessibility and utilization of maternal and newborn healthcare services in Ghana after user-fee abolition. BMC Pregnancy Childbirth. 2014;14:425. doi:10.1186/s12884-014-0425-8

13. Yakong V, Rush K, Bassett-Smith J, Bottorff J, Robinson C. Women's experiences of seeking reproductive health care in rural Ghana: challenges for maternal health service utilization. $J A d v$ Nurs. 2010;66(11):2431-2441. doi:10.1111/j.1365-2648.2010.05404.x

14. Nakua KE, Sevugu TJ, Dzomeku MV, Otupiri E, Lipkovich RH, Owusu-Dabo E. Home birth without skilled attendants despite millennium villages project intervention in Ghana: insight from a survey of women's perceptions of skilled obstetric care. BMC Pregnancy Childbirth. 2015;15:243. doi:10.1186/s12884-015-0674-1

15. Adatara P. Factors influencing the utilisation or non-utilisation of skilled delivery services: perspectives of mothers from Bongo District. Am J Public Health. 2015;3(1): 27-32
16. Bazzano A, Kirkwood B, Tawiah-Agyemang C, Owusu-Agyei S, Adongo P. Beyond symptom recognition: care-seeking for ill newborns in rural Ghana. Trop Med Int Health. 2008;13(1):123-128. doi:10.1111/j.1365-3156.2007.01981.x

17. Sychareun V, Hansana V, Somphet V, Xayavong S, Phengsavanh A, Popenoe R. Reasons rural Laotians choose home deliveries over delivery at health facilities: a qualitative study. BMC Pregnancy Childbirth. 2012;12:86. doi:10.1186/1471-2393-12-86

18. Sialubanje C, Massar K, Hamer DH, Ruiter RA. Reasons for home delivery and use of traditional birth attendants in rural Zambia: a qualitative study. BMC Pregnancy Childbirth. 2015;15:216. doi:10.1186/s12884-015-0652-7

19. Sarker BK, Rahman M, Rahman T, Hossain J, Reichenbach L, Mitra DK. Reasons for preference of home delivery with traditional birth attendants (TBAs) in rural Bangladesh: a qualitative exploration. PLoS One. 2016;11(1):e0146161. Leone T, ed. DOI:10.1371/journal.pone. 0146161

20. Lori JR, Boyle JS. Cultural childbirth practices, beliefs, and traditions in postconflict Liberia. Health Care Women Int. 2011;32(6):454-473. doi:10.1080/07399332.2011.555831

21. Chapman R. Chikotsa - secrets, silence, and hiding: social risk and reproductive vulnerability in central Mozambique. Med Anthropol $Q$. 2006;20:487-515. doi:10.1525/maq.2006.20.4.487

22. Berry N. Kaqchikel midwives, home births, and emergency obstetric referrals in Guatemala: contextualizing the choice to stay home. Soc Sci Med. 2006;62:1958-1969. doi:10.1016/j. socscimed.2005.09.005

23. Nyefene M, Ayanore MA, Adatara P, Groot M, Milena Pavlova M. Barriers to the utilisation of facility-based birthing services in rural Northern Ghana. Afr J Midwifery Women's Health. 2018;12 (3):121-129. doi:10.12968/ajmw.2018.12.3.121

24. Sharma S, van Teijlingen E, Hundley V, Angell C, Simkhada P. Dirty and 40 days in the wilderness: eliciting childbirth and postnatal cultural practices and beliefs in Nepal. $B M C$ Pregnancy Childbirth. 2016;16:147. doi:10.1186/s12884-0160982-0

25. Downe S, Finlayson K, Oladapo O, Bonet M, Gülmezoglu AM. What matters to women during childbirth: a systematic qualitative review. PLoS One. 2018;13(4):e0194906. Most healthy childbearing women want a positive birth experience. Safety and psychosocial wellbeing are equally valued. Maternity care should be designed to fulfil or exceed women's' personal and socio-cultural beliefs and expectations. DOI:10.1371/journal. pone. 0194906

\section{Publish your work in this journal}

The International Journal of Women's Health is an international, peerreviewed open-access journal publishing original research, reports, editorials, reviews and commentaries on all aspects of women's healthcare including gynecology, obstetrics, and breast cancer. The manuscript management system is completely online and includes a very quick and fair peer-review system, which is all easy to use. Visit http://www.dovepress.com/testimonials.php to read real quotes from published authors. 